\title{
Towards Design Principles for Data-Driven Services in Industrial Environments
}

\author{
Can Azkan \\ Fraunhofer ISST \\ Can.Azkan@isst.fraunhofer.de \\ Frederik Möller \\ TU Dortmund University \\ Fraunhofer ISST \\ Frederik.Moeller@tu-dortmund.de
}

\begin{abstract}
The ever-growing amounts of data offer companies many opportunities to exploit them. Resulting datadriven services hold great potential for creating unique value for customers and the achievement of competitive advantages. Nevertheless, especially companies in the industrial environment struggle to implement successful data-driven service innovations. Surprisingly, there is a lack of scientific research addressing this issue. Thus, our research generates design principles for data-driven services to aid in their development. For this purpose, we present a qualitative interview study with experts in different lines of businesses among the industry sector, holding varying positions and roles in service systems. Through practical examples, we show which challenges exist in the development and use of datadriven services. On this basis, we derive design principles to help understanding data-driven services and to overcome difficulties identified in practice, notably, that allows practitioners to develop new services or re-design existing ones.
\end{abstract}

\section{Introduction}

In the course of the digital transformation, the rise of digitally connected products and services leads to large amounts of data. In combination with advanced analytics techniques, data are the key resource to create new business opportunities for service innovation and to generate novel value for customers [1-3]. Offering these new data-driven services such as condition monitoring or predictive maintenance enables manufacturers to strengthen their market position and gain further competitive advantages [4, 5]. By integrating the customer in the process of

\author{
Lennart Iggena \\ Fraunhofer ISST \\ Lennart.Iggena@isst.fraunhofer.de \\ Boris Otto \\ TU Dortmund University \\ Fraunhofer ISST \\ Boris.Otto@tu-dortmund.de
}

innovation, firms conduct a new sense of value cocreation through cross-company data exchange [6].

However, service innovation is no straight path forward, and product-centric firms struggle with enhancing their existing or creating new services [7]. Traditionally, innovation for product development differs immensely from service innovation approaches, especially for data-driven services. Even if many authors address this issue by providing specific service innovation frameworks, like in [8], achievements in the real world are still scarce. Recent studies show that companies often suffer from a lack of technical experts or a lack of a strategy for developing data-driven services [9]. Others find that approximately half of all service providers realize only moderate revenues, while $25 \%$ lose money [10]. Moreover, in contrast to traditional industrial services, the development of data-driven services is much more complicated as it requires advanced technologies and sweeping IT skills, among other new capabilities [11].

Against this background, the present state of research reveals a surprising shortage of empirical studies aimed at exploring the use of data and analytics for service innovation in practice. Yet, such work is essential to make theories and methods relevant to the field [12].

Therefore, the presented paper aims to discover design knowledge for developing data-driven services within the industrial environment as part of service innovation. The process of new service development can be conducted in a service design approach, which is a formalized, multi-disciplinary concept that aids to innovate service offerings [13]. In that context, design principles are meant to codify design knowledge and, considering the respective boundaries, to enable its reuse [14]. We propose a design science research (DSR) by tackling the following Research Question: How should data-driven services in industrial environments be designed in order to compete successfully? 
To answer this question, we conduct interviews with various industrial companies, that use or create such data-driven services, and scientists as well as consultants to identify success factors and challenges. The structure of these interviews is based on previous work in which a systematic literature review and analysis of 100 data-driven services in manufacturing industries was carried out to derive the characteristics of such data-driven services in the form of a taxonomy [6]. Since that, the success of a data-driven service can be stated among the dimensions of value creation, value delivery, and value capture.

The paper is organized as follows. After the introduction, we give an overview of the relevant theoretical background, i.e., data-driven services and service innovation. Our research methodology follows in section 3. Section 4 contains our findings, from the derived meta-requirements to the resulting design principles. Finally, while discussing our results in section 5, we offer both business and scientific implications in section 6 , considering constraints and future research.

\section{Theoretical Background}

\subsection{Data-Driven Services}

Due to the rapidly expanding use of information and communication technology in industrial companies, the challenge of creating new services is becoming more complex [11]. In the past, companies used data and analytics mainly for internal business processes and to derive insights for making managerial decisions [15]. Nowadays, companies focus more and more on developing digital service offerings, besides their range of traditional services like maintenance and repair, to add further value to their existing products $[2,11]$. Therefore, data-driven services (DDS) evolve, characterized by the fact that data are used as the key resource $[6,16,17]$. Continuing digitization trends like the internet of things and cloud computing facilitate data generation and data processing, which amplifies the creation of data-driven services [18].

In an original research paper [6], the authors conceptualized the nature of data-driven services by building a taxonomy that helped to gain a deeper understanding of their structure and to identify corresponding characteristics of DDS. The focus of data-driven services lies in the use and analysis of data with the ultimate goal to support the improved business decision-making process of the customer based on sound, data-based insights [19, 20].

Service innovations occur in service systems representing configurations of organizations, technologies, and other resources, like data that interact with other service systems to create mutual value [21]. While product-service systems include tangible products and intangible services to fulfill customer needs [22], we refer to the concept of service systems since data-driven services concentrate on data as a key resource and fade out the product layer. Service systems are dynamic, as they are composing, recomposing, and decomposing over time [23]. To support new data-driven services, the actors in a service system interact and collaborate to find, exchange, consume, or use data to contribute to the value that emerges for the customer and other actors as well, which is labeled as value co-creation [24]. Service providers might actively search for external data assets which will contribute to and enrich their service offering. Hence, besides the service provider and service user, the role of data provider occurs who acts as a co-producer since he delivers valuable data for service innovations [25, 26]. We focus on these three roles in a service system that co-create value even though we know that further roles might appear [27].

Data-driven services offer benefits for customers and provide companies through generation, collection, analysis and/or combination of internal and external data [28]. Thus, data and analytics give much more indepth access to the customer by transforming customer-related data into information that directly supports the service offering [29]. That leads to a closer relationship with the customer and ensures stable revenue streams and closer ties that are difficult for competitors to break [30].

Nevertheless, many product-centric companies struggle to perform the transition toward services. Service orientation often includes a significant shift to a new strategic direction, a new organizational structure, and new skills [31]. Therefore, the process of data-driven service innovation needs definite design principles to overcome this issue.

\subsection{Service Innovation and Service Design for Data-Driven Services}

Over the last years, we see a significant growth of scientific interest in the field of service innovation [32, 33]. Service innovation has traditionally focused on the development of new service offerings and concepts, as well as how to generate new ideas and develop customer-driven solutions [7]. Thus, service innovation is defined as the "rebundling of diverse resources that create novel resources that are beneficial (i.e., value experiencing) to some actors in a given context" [34]. As a result of increasing competition and shifting technologies, service 
organizations, as well as manufacturers, must innovate and adjust their services to remain viable [35]. The process of innovation can be conducted in two ways. While continuous service innovations aim at improving existing services, discontinuous service innovations offer the potential to create radically new service offers and processes through innovation leaps [36]. Furthermore, service innovation is pursued in strong interaction with customers or in co-creation with business partners. That can considerably influence and enhance the developed service as external actors integrate their knowledge and experiences [33].

There are many research perspectives and different angles on service innovation like [33] outline. Terms that occur, amongst other things, are service engineering or service design. They all address the question of how new services can be developed and commercialized. Service engineering describes a technical discipline and refers to a more processual and systematic development and design of services using appropriate models, methods, and (software) tools [37]. On the contrary, service design adopts a design thinking approach that contains several stages to create new innovative services [38, 39]. It is described as a multi-disciplinary approach in which service design teams benefit from their interdisciplinary members having different backgrounds, areas of knowledge, and competencies [13]. Therefore, service design poses a suitable way of guiding and advancing the development of data-driven services [40]. The fundamental process of new service development consists of five essential steps that are 1) opportunity identification, 2) customer understanding, 3) concept development, 4) process design and 5) refinement and implementation [41]. Since design principles are understood "as fundamental propositions that aid designers in achieving a successful transfer of requirements to design" [42], we aim to support the activity of concept design, which generates the service concept based on service possibilities and customer needs [41].

Similar research carried out by [13] provides design principles for analytics-based services.
Although their nature resembles data-driven services, there is no sector focus set so that the principles are broadly held generic. The six principles provided by [11] focus on industrial companies, though, but we see the necessity to enhance that topic from a design science perspective. Other IS research in this field contributes to design principles for data-driven business models [43] or digital value co-creation networks [44]. Additionally, only a few studies focus on developing data-driven services in an industrial context at all [11]. Thus, there are not yet any design principles for data-driven services holding a focal point on companies within the industrial environment.

\section{Research Design}

\subsection{Design Principle Construction}

Design Principles are prescriptive guidelines for action that are supposed to enable designers to bring about an artifact more efficiently once they are used [42]. There are various ways to generate design principles reflectively, e.g., through formalizing and codifying experience of designers. In the present case, the design principles are developed a priori as they are intended to support the development of novel datadriven services by synthesizing data from the field.

We follow the recommendations of [42], as it is a method explicitly tailored for design principle generation and includes interviews as an underlying knowledge base. The present research is part of a more extensive design science research (DSR) project, which encompasses multiple artifacts in the domain of data-driven services in manufacturing (e.g., taxonomies). DSR is particularly suitable for solving real-world problems by systematically conceptualizing and developing artifacts [45]. Our DSR approach, proposed by [46], consists of problem awareness, suggestion, development, and an evaluation phase and multiple design cycles.

The research approach chosen to develop design principles is a qualitative interview study. The knowledge base from which we draw our data are

Table 1. Interviewed experts by industry, position, role and duration

\begin{tabular}{|l|l|l|l|l|}
\hline Industry & Employees & Positions & Role & Duration [min] \\
\hline Production & 20.000 & Project manager & Service Provider & $27: 31$ \\
\hline Production & 20.000 & Service manager & Service Provider & $43: 32$ \\
\hline Information technology & 62 & Sales Manager & Data Provider & $34: 51$ \\
\hline Information technology & 62 & Project Manager & Data Provider & $27: 03$ \\
\hline Logistics & 8 & Scientist / Consultant & - & $57: 16$ \\
\hline Automotive & 95 & Scientist / Consultant & - & $26: 32$ \\
\hline Chemical industry & 11.236 & Plant Manager & Service User & $30: 15$ \\
\hline Manufacturing & 18.000 & Project Manager & Service User & $41: 39$ \\
\hline Manufacturing & 238 & Development Manager & Service Provider & $77: 28$ \\
\hline
\end{tabular}


interviews with experts from the field and applied research (see Table 1). The study at hand relies on qualitative data collected in expert interviews that know the domain of data-driven services. Nevertheless, qualitative interviews with experts are an established method to generate data in the Information Systems field [47]. A priori, we prepared an interview guide to ensure that a similar range of topics is discussed with the interviewees, making the interview semi-structured [48]. From the interviews, we elicited meta-requirements, i.e., requirements that apply to a class of artifacts [42] rather than a single instance alone. Subsequently, we formulate design principles as prescriptive guidelines derived from the meta-requirements and address at least one of them. The explicit, linguistic formulation draws from the template of [49].

In the initial problem awareness phase of design cycle one, two separate literature analyses were conducted to gain a deeper understanding of value cocreation through data exchange and data-driven services $[6,25]$. As a result, the authors found out that many companies in the industrial environment face challenges in developing data-driven services.

\subsection{Qualitative Study}

To gain a deeper understanding of data-driven services and their respective challenges, this paper includes interviews with practitioners who contribute to the creation, provision, and use of services. Given the fact that service design is an interdisciplinary approach that calls for various perspectives from different disciplines and positions, we chose our interview partners along with the here relevant roles of a service system [50]. The selected interview partners are from various areas such as sales, project, operations manager, and consultants. This has ensured that different aspects, including existing challenges and obstacles in the creation and use of data-driven services, are taken into account. The interview guide followed the structure of the developed taxonomy by [6]. We have asked the areas of value creation, value delivery, and value capture. This ensured that all dimensions that characterize a service are considered $[51,52]$. Here the experts stated various challenges that arise in different areas. While, e.g., some highlighted the issue of convincing potential customers of the service, others see the right data quality as major challenge. The chosen experts stem from industrial and scientific consortium partners of a research project which explored data as production

Table 2. Meta-Requirements with example quotes

\begin{tabular}{|c|c|c|}
\hline$\#$ & Meta-Requirement & Example Quotes (excerpt) \\
\hline MR 1 & $\begin{array}{l}\text { The added value of data- } \\
\text { driven services must be } \\
\text { made clear in both } \\
\text { technical and economic } \\
\text { terms. }\end{array}$ & $\begin{array}{l}\text { "If the customer can achieve a higher profit by using our data-driven } \\
\text { services, we receive a percentage of the increased profit" (Service Provider) } \\
\text { "In the end, it's a simple cost-benefit calculation. If I end up with a data- } \\
\text { driven service, do I have a saving or such a strong profit in sales that it is } \\
\text { worth using a data-driven service." (Scientist/ Consultant) }\end{array}$ \\
\hline MR 2 & $\begin{array}{l}\text { Bundle different data sets } \\
\text { and data sources to obtain } \\
\text { and predict more in-depth } \\
\text { information about the } \\
\text { production process. }\end{array}$ & $\begin{array}{l}\text { "Only when we recorded the weather data of the plant in Siberia, we were } \\
\text { able to identify that a snowstorm had caused the production problems." } \\
\text { (Service Provider) } \\
\text { "Existing optimization models are based on data silos. As a result, these are } \\
\text { inflexible, take into account a too limited process section and are therefore } \\
\text { not used in operations." (Service User) }\end{array}$ \\
\hline MR 3 & $\begin{array}{l}\text { It must be ensured that the } \\
\text { quality of the data is } \\
\text { sufficiently high, and } \\
\text { sensors work properly in } \\
\text { manufacturing conditions. }\end{array}$ & $\begin{array}{l}\text { "Sensors and measurement technology are fine components. The use in } \\
\text { crushing machines leads to many false alarms, e.g. because the sensors get } \\
\text { dusty. This leads to the fact that the data is not usable for data-based } \\
\text { services." (Service Provider) } \\
\text { "Used sensors are sensitive to fluctuations, which are due to temperature } \\
\text { fluctuations, for example." (Service Provider) }\end{array}$ \\
\hline MR 4 & $\begin{array}{l}\text { Secure data exchange } \\
\text { must be the cornerstone of } \\
\text { every data-driven service } \\
\text { creation. }\end{array}$ & $\begin{array}{l}\text { "There is no discussion about data security” (Service Provider) } \\
\text { "If the IT-security standards of external partners are as high as ours } \\
\text { internally in terms of data exchange, we could consider exchanging data } \\
\text { with external partners." (Service User) }\end{array}$ \\
\hline
\end{tabular}


factor for new services and as product itself. Given that, the quantity of interviewees is restricted which should be extended prospectively. In total, we conducted nine interviews that were recorded and transcribed anonymously. We used qualitative context analysis to analyze the interviews [53]. In the paper, we follow the recommendation of [54] and substantiate our findings with power quotes, i.e., those quotes that strikingly underlines the point that we tried to make (see Table 2).

The entire research activities, the systematic literature analyses, taxonomy development, and interviews with practitioners form the basis for developing the design principles for data-driven services in industrial environments.

\section{Results}

First, meta-requirements are a mandatory part of design principle development [42] and ensure value grounding, i.e., that no design principle is without an intended requirement that it aims to fulfill [55]. Metarequirements necessarily need to be general enough so that they are transferable to multiple artifacts of the same class and decoupled from the application scenario that they were derived from [56]. The created meta-requirements (see Table 2) address significant challenges in creating data-driven services that still arise nowadays. The interviews revealed that fundamental aspects of service science still need to be made clear for practitioners.

The design principles explained below are seen as linguistic, prescriptive statements for action that respond to the meta-requirements elicited above. Therefore, they are derived from the metarequirements, which, in turn, stemmed from the statements of the interviewees.

In order to structure the design principles, we draw from the dimensions of the taxonomy of data-driven services in manufacturing industries, as proposed by [6]. Using these dimensions ensures that the design principles cover, comprehensively, issues that are necessary to data-driven service design. Thus, we draw from 11 dimensions that are thematically categorized into three higher-level meta-dimensions that characterize a service: value creation, value delivery, and value capture (see Table 3 ).

Table 3. Dimensions of Data-Driven Services according to [6]

\begin{tabular}{|l|l|}
\hline Dimension & Definition \\
\hline Value Creation \\
\hline Main Value & $\begin{array}{l}\text {... describes the value proposition } \\
\text { behind a data-driven service. }\end{array}$ \\
\hline
\end{tabular}

\begin{tabular}{|c|c|}
\hline $\begin{array}{l}\text { Main } \\
\text { Outcome }\end{array}$ & $\begin{array}{l}\text {.. benefits for the customers, such } \\
\text { as cost reductions, time savings, or } \\
\text { increased flexibility through } \\
\text { efficiency gains. }\end{array}$ \\
\hline $\begin{array}{l}\text { Analytics } \\
\text { Type }\end{array}$ & $\begin{array}{l}\text {.. four different types, ranging } \\
\text { from descriptive analyses to } \\
\text { prescriptive analyses. }\end{array}$ \\
\hline Data Sources & $\begin{array}{l}\text {...describes the origin of the data. } \\
\text { A distinction is made between } \\
\text { internal and external sources. }\end{array}$ \\
\hline Data Types & ...specifies the content of the data. \\
\hline $\begin{array}{l}\text { Aggregation } \\
\text { Level }\end{array}$ & $\begin{array}{l}\ldots \text { single or multiple aggregation } \\
\text { levels (number of data sources). }\end{array}$ \\
\hline \multicolumn{2}{|c|}{ Value Delivery } \\
\hline $\begin{array}{l}\text { Service } \\
\text { Delivery }\end{array}$ & $\begin{array}{l}\ldots \text { the way the customer interacts } \\
\text { with the service. }\end{array}$ \\
\hline Service Flow & $\begin{array}{l}\ldots \text { frequency at which the service is } \\
\text { made available. }\end{array}$ \\
\hline $\begin{array}{l}\text { Platform } \\
\text { Type }\end{array}$ & $\begin{array}{l}\ldots \text { type of platform the service } \\
\text { uses. }\end{array}$ \\
\hline \multicolumn{2}{|c|}{ Value Capture } \\
\hline $\begin{array}{l}\text { Pricing } \\
\text { Model }\end{array}$ & ... how the service is monetized. \\
\hline $\begin{array}{l}\text { Payment } \\
\text { Mode }\end{array}$ & $\begin{array}{l}\text {... how the customer pays for the } \\
\text { service. }\end{array}$ \\
\hline
\end{tabular}

\section{Design Principles for Data-Driven Services in Industrial Environments}

Based on the preceding meta-requirements and the characteristics of data-driven services, we derive six design principles in total. The first design principle concerns the added value of data-driven services, according to MR1. A central issue highlighted by the interviewees is the lack of awareness of the value of data. During the interviews, it became clear that service users often do not know why they should use such services. Therefore, they are very hesitant about sharing data. Thus, a vital task for developing successful data-driven services is to communicate, explain, and demonstrate the value of these services, which leads us to the first design principle:

DP1: Provide the user/customer of data-driven services with adequate information on potential returns on investment, i.e., through highlighting technical key performance indicators.

In the development of data-driven services, it has become clear that, for example, the combination of different data sources can yield entirely new insights. In a concrete use case, the reason for the deviating product quality could be determined by combining process data and weather data. Here, a snowstorm on 
Siberia had meant that limestone could not be ground as planned in cement production. Therefore, the second design principle is as follows:

DP2: Provide the data-driven service with mechanisms to leverage product and process data from production as well as additional external data in order to generate the most optimal configuration of data-driven value for the customer.

Another aspect concerns the evaluation of data records from machines and systems. It becomes clear that operational processes in manufacturing industries are very complex and, in some cases, unique. To make use of the data and create services that enhance those knowledge-intensive production processes, expert knowledge, and experience are needed. As a result, data scientists from non-industry sectors, for example, cannot evaluate the collected data sets adequately and derive useful recommendations for action. Therefore, regarding MR1 and MR2, we formulate the third design principle:

DP3: Provide the data-driven service with sufficient underlying expert knowledge and skills in order to achieve the most profound and reliable results in data-driven value creation.

Another important aspect addressed by MR3 is the quality of the data collected from the production processes. The quality of the data determines the quality of the services. For example, intense vibrations or high temperatures might interfere with the sensors working correctly. In the mining and exploration environment, several interviewers reported that rough environments could damage the sensors or cover them with dust. This leads to the fact that the data collection is not correct, and therefore, the analyses on it give false results. We formulate the fourth design principle as follows:

DP4: Provide the data collecting sensors with a mechanism to prevent contamination through environmental factors, e.g., dust, so that the underlying data of data-driven services is of high quality and produces correct results.

The cornerstone of data-driven services is crosscompany data exchange, as pointed out by MR4. This clearly shows that many companies are still worried about data security and the loss of IP-relevant knowledge. While companies can ensure internally that all security requirements are met, it is not clear that external companies can also fulfill them. It is, therefore, essential, especially as a service provider who processes data, to take care of security aspects for the company providing data. Furthermore, the owner of the data should determine the terms of use of his data assets and thus preserve the data sovereignty, which leads to trust and transparency between the service provider and user. Subsequently, the fifth design principle is:

DP5: Provide data security and sovereignty among all data-related activities to foster customers' trust, in the provision of data-driven services.

Along with MR1 and MR2, the pricing of services is a key factor for their success. The pricing model must be designed in such a way that the customer can and wants to take advantage of the services. While, for example, subscription models are widespread in the B2C sector, the interviews revealed that corporate customers only want to make one-time payments for accounting reasons. Performance-based models might be used as well to convince customers of the added value of the service. That means that the service provider receives a percentage share of the additional profit generated by the service. The sixth and final design principle is, therefore

DP6: Provide the data-driven service with suitable pricing to generate revenue for securing sustainable success.

In sum, these meta-requirements and design principles serve as the theoretical guidelines for the development of data-driven services in industrial environments.

\section{Discussion}

The introduced design principles give initial orientation for the development of data-driven services in industrial environments. According to [57], our results align with the theory type 'design and action' since the design principles provide action advice. Nevertheless, a concrete method for the development of data-driven services has to be derived from the presented principles. Yet, the results of this research address the new challenges emerging from handling data as a key resource for service innovation.

For instance, data quality proves to be the pillar of successful data-driven services [58]. Therefore, the functionality of sensors must be guaranteed all the time as one expert indicates, that, e.g., cement processing sensors can be covered in dust, which leads to incomplete data capture and hence, poor data quality and indecisive service performance. To 
generate more understanding of processes and machines and optimize services, another expert states that data of some specific events are stored separately, like the start of grinding machines. Here, sensors must be able to handle considerable vibrations to maintain sufficient data quality as well. The automatic data generation by sensors in rough and dynamic conditions is specific for industrial environments.

Even though the early integration of customers in the service innovation process might be the most stated principle in service science [34], the interviews revealed that many companies still leave their customer needs out. That might be because existing literature often only focusses on B2C relationships [59]. Given increased customer demands, service providers in the B2B-segment should follow an early customer involvement as it sparks stronger customer loyalty and higher market success [11]. Often customers do not see the value that a data-driven service brings because of its intangibility and novelty. By speaking to the customer, companies can identify issues and directly meet the needs through new services [20]. In terms of customers, we are not only regarding external customers. Frequently, e.g., datadriven services are also provided within a company by internal service departments for plant operators.

Here, besides one-to-one conservations, workshops with several internal/external customers and partners turned out to be a fruitful method to generate ideas for service innovation. Since customers still might hesitate to share their data because they fear losing control and disclosing business secrets, companies must implement mechanisms to guarantee data security and sovereignty and clarify policies for data usage [60]. Another way of meeting the security requirements of service users was to create the services directly on the machine. For this purpose, edge computing can be used to process and analyze the data instantly on site. The disadvantage here is that the service provider cannot directly optimize the underlying algorithms in such a case and react rapidly to contradictory analysis results.

Another essential aspect concerns the transparency of data-driven services. It turns out that service users are reluctant to use services if they do not understand how the results are obtained. This is caused when services are developed without customer involvement. Therefore, service users tend to reject the service at all, as it does not meet their expectations. That underlines the need for early integration of customers again as well as clear communication of benefits.

Data security builds another major aspect to convince customers of the data-driven service. The experts showed the consensus that data protection and security mechanisms are crucial. Firms in the industry sector in particular, fear the loss of data and therefore of sensitive information of production processes and operating secrets.

We also observed internal challenges within large companies. For the development of data-driven services, interdisciplinary teams are needed, consisting of representatives from service and IT departments and further company functions [2]. Missing allocation of responsibilities results in different initiatives that require unnecessary workload and resources. Thus, clear governance structures and coordinated projects create shared consciousness resulting in success [61]. Another aspect lies in evaluating data as an asset and finding the right pricing for a data-driven service. Companies must identify those approaches which fit the most to the service offering and the customer's interests [17]. Data itself can represent a payment method in non-monetary terms since the collected data could be used to improve internal processes or be sold to third parties like data marketplaces [6].

Finally, the interviews also revealed that a variety of skills is needed to create data-driven services. That starts with the correct provision of data, continues with the development of software and hardware components, and ends with evaluating the analyzed data [19]. Therefore, broad domain knowledge and engineering skills are necessary to generate reliable insights as processes and procedures are highly specific in industrial environments. To provide datadriven services, the respective companies, among other things, focus on their core competencies and make targeted use of external services. That was shown, for example, by the fact that mechanical engineering companies often do not have sufficient data analysis knowledge to offer services on their own. In this case, a start-up helped to develop self-learning algorithms in close cooperation with the process engineers of the mechanical engineering company.

The design principles highlight the need of data exchange between customers and providers for value co-creation. Therefore data-driven services are highly customer-centric and demand longterm relationships from which all actors in the service system benefit. Our results can guide practitioners and form the base for future research, as pointed out in the following section.

\section{Conclusion and Future Research}

Data-driven services in industrial environments make use of the immensely growing data amounts from new technologies by analyzing them to create new value for customers. As they deliver context- 
relevant insights or support reliable decision-making, data-driven services promise competitive advantages and new revenue streams for providing companies. Since data form the key resource, data exchange leads to a new kind of value co-creation of which service provider and user benefit. There is a surprising lack of scientific literature regarding the systematic development and design of data-driven services. As a result, service design teams in industrial companies struggle to build service concepts that lead to successful and lasting services. Our research addresses this issue and conceptualizes initial design knowledge into four meta-requirements and six design principles for supporting practitioners and scientists in understanding and successfully creating data-driven services. By doing so, we take existing research a step further and create domain-specific insights.

The contribution of managers is to provide basic information on key aspects and principles of how DDS should be designed. These help to reflect their own service concepts on the one hand and, on the other hand, to design DDS from scratch. The design principles show which aspects have to be taken into account when developing DDS. In particular, they highlight the importance of customer involvement in the service innovation process, which leads to value co-creation through data exchange. Even if the design principles are held generic to offer flexibility, the focus on industrial companies offers concrete recommendations of action, which makes their application into practice intuitive and straightforward.

For scientific contributions, the description of the design process enables a scientific validation and extension of the artifact. The design principles are the first step into generating comprehensive design guidelines for data-driven services in industrial environments and serve as a foundation stone for other sectors. The design principles produce inductive insights and deep understanding of the manufacturing domain.

The research also has underlying limitations. In particular, the results from the explorative focus group interviews are limited in their generalizability. Other experts might have given different answers leading to other MR and DP. Furthermore, design principles solely are by no means a guarantee for success.

Further research should continue the subsequent design science research by carrying out instantiation or field testing to evaluate the compiled design principles. By now our results are initial hypotheses that need to be validated. Additionally, more data sources (e.g., further interviews, case studies) should be used to triangulate a more comprehensive look into DDS in industrial environments. This also includes firms of various sizes and from different countries to gain insights from different views. In a next step, the results should form the basis for a method for developing data-driven services that provides recommendation for action in a structured manner. Apart from this, the application in other sectors might be considered, leading to new findings and enhancing our results potentially.

The results of our empirical study are promising and provide substantial knowledge for further improvements in the following design cycles. Thus, this research can guide practitioners in developing new data-driven services and supports scientific comprehension of designing data-driven services in industrial environments.

\section{Acknowledgment}

This research and development project is funded by the German Federal Ministry of Education and Research (BMBF) within the Innovations for Tomorrow's Production, Services, and Work (funding number 02K18D130) and implemented by the Project Management Agency Karlsruhe (PTKA).

\section{References}

[1] Brynjolfsson, E. and A. McAfee, "The Business of Artificial Intelligence: What It Can - and Cannot - Do for Your Organization", Harvard Business Review, 95, 2017, pp. 3-11.

[2] Hans-Jörg Bullinger, T. Meiren, and R. Nägele, Smart Services in Manufacturing Companies, 2015.

[3] Huang, M.-H. and R.T. Rust, "Technology-driven service strategy", Journal of the Academy of Marketing Science, 45(6), 2017, pp. 906-924.

[4] Demirkan, H., C. Bess, J. Spohrer, A. Rayes, D. Allen, and Y. Moghaddam, "Innovations with Smart Service Systems: Analytics, Big Data, Cognitive Assistance, and the Internet of Everything", Communications of the Association for Information Systems, 37, 2015.

[5] Zambetti, M., R. Pinto, and G. Pezzotta, "Data lifecycle and technology-based opportunities in new Product Service System offering towards a multidimensional framework", Procedia CIRP, 83, 2019, pp. 163-169.

[6] Azkan, C., L. Iggena, I. Gür, F. Möller, and B. Otto, "A Taxonomy for Data-Driven Services in Manufacturing Industries", in Proceedings of the 24th Pacific Asia Conference on Information Systems (PACIS). 2020.

[7] Kindström, D. and C. Kowalkowski, "Service innovation in product-centric firms: a multidimensional business model perspective", JBIM, 29(2), 2014, pp. 96-111.

[8] Zheng, P., T.-J. Lin, C.-H. Chen, and X. Xu, "A systematic design approach for service innovation of smart 
product-service systems", Journal of Cleaner Production, 201, 2018, pp. 657-667.

[9] Azkan, C., L. Iggena, L. Meisel, M. Spiekermann, T. Korte, B. Otto, V. Demary, H. Goecke, and A. Krotova, DEMAND Use Case Report: Perspektiven der Datenwirtschaft, 2020.

[10] Stanley, J. and P. Wojcik, "Better B2B Selling", McKinsey Quarterly, 38(3), 2005.

[11] Kampker, A., M. Husmann, T. Harland, P. Jussen, and M. Steinbauer, "Six Principles for Successful Data-Driven Service Innovation in Industrial Companies", in Proceedings of the 24th International Conference on Engineering, Technology and Innovation (ICE/ITMC). 2018: Stuttgart, Germany.

[12] Lim, C., M.-J. Kim, K.-H. Kim, K.-J. Kim, and P.P. Maglio, "Using data to advance service: managerial issues and theoretical implications from action research", JSTP, 28(1), 2018, pp. 99-128.

[13] Hunke, F. and F. Kiefer, "Designing Analytics-Based Services - Exploring Design Requirements for Methodological Tool Assistance in Service Design Teams", in Proceedings of the 15th International Conference on Wirtschaftsinformatik. 2020: Potsdam, Germany.

[14] Chandra Kruse, L., S. Seidel, and S. Purao, "Making Use of Design Principles", in Tackling society's grand challenge with design science: 11th international conference, DESRIST 2016, St. John's, NL, Canada, May 23-25, 2016 : proceedings, J. Parsons, Editor. 2016. Springer: Cham, Heidelberg.

[15] McAfee, A. and E. Brynjolfsson, "Big Data: The Management Revolution", in HBR. 2012.

[16] Hartmann, P.M., M. Zaki, N. Feldmann, and A. Neely, "Capturing value from big data - a taxonomy of data-driven business models used by start-up firms", IJPEM, 36(10), 2016, pp. 1382-1406.

[17] Schüritz, R., S. Seebacher, and R. Dorner, "Capturing Value from Data: Revenue Models for Data-Driven Services", in Proceedings of the 50th Hawaii International Conference on System Sciences (2017), Hawaii International Conference on System Sciences. 2017. Hawaii International Conference on System Sciences.

[18] Yoo, Y., R.J. Boland, K. Lyytinen, and A. Majchrzak, "Organizing for Innovation in the Digitized World", Organization Science, 23(5), 2012, pp. 1398-1408.

[19] Chen, H., R. Chiang, and V. Storey, "Business intelligence and analytics: from big data to big impact", MIS Quarterly, 36(4), 2012, pp. 1165-1188.

[20] Schüritz, R., B. Wixom, K. Farrell, and G. Satzger, "Value Co-Creation in Data-Driven Services: Towards a Deeper Understanding of the Joint Sphere", in Proceedings of the 40th International Conference on Information Systems (ICIS). 2019: Munich, Germany.

[21] Spohrer, J., S.L. Vargo, N. Caswell, and P.P. Maglio, "The service system is the basic abstraction of service science", in Proceedings of the 41st Hawaii International International Conference on Systems Science (HICSS). 2008: Waikoloa, Big Island, HI, USA.

[22] Mont, O.K., "Clarifying the concept of product-service system", Journal of Cleaner Production, 10(3), 2002, pp. 237-245.

[23] Beverungen, D., C.F. Breidbach, J. Poeppelbuss, and V.K. Tuunainen, "Smart service systems: An interdisciplinary perspective", Information Systems Journal, 29(6), 2019, pp. 1201-1206.

[24] Vargo, S.L. and R.F. Lusch, "Service-dominant logic: continuing the evolution", Journal of the Academy of Marketing Science, 36(1), 2008, pp. 1-10.

[25] Azkan, C., F. Möller, L. Meisel, and B. Otto, "Service Dominant Logic Perspective on Data Ecosystems - A Case Study based Morphology", in Proceedings of the 28th European Conference on Information Systems (ECIS), Marrakesh, Morocco. 2020.

[26] Grönroos, C., "On Value and Value Creation in Service: A Management Perspective", Journal of Creating Value, 3(2), 2017, pp. 125-141.

[27] Maglio, P.P., S.L. Vargo, N. Caswell, and J. Spohrer, "The service system is the basic abstraction of service science", Information Systems and e-Business Management, 7(4), 2009, pp. 395-406.

[28] Kampker, A., M. Husmann, P. Jussen, and L. Schwerdt, "Market Launch Process of Data-Driven Services for Manufacturers: A Qualitative Guideline", in Exploring Service Science, G. Satzger, L. Patrício, M. Zaki, N. Kühl, and P. Hottum, Editors. 2018. Springer International Publishing: Cham.

[29] Hunke, F., C. Engel, R. Schüritz, and P. Ebel, "Understanding the anatomy of analytics-based services - A taxonomy to conceptualize the use of data and analytics in services", in Proceedings of the 27th European Conference on Information Systems (ECIS). 2019: Stockholm \& Uppsala, Sweden.

[30] Herterich, M.M., F. Uebernickel, and W. Brenner, "The Impact of Cyber-physical Systems on Industrial Services in Manufacturing", Procedia CIRP, 30, 2015, pp. 323-328.

[31] Kindström, D., C. Kowalkowski, and E. Sandberg, "Enabling service innovation: A dynamic capabilities approach", Journal of Business Research, 66(8), 2013, pp. 1063-1073.

[32] Breidbach, C.F. and P.P. Maglio, "A Service Science Perspective on the Role of ICT in Service Innovation", in ECIS 2015. 2015.

[33] Engel, C. and P. Ebel, "Data-driven Service Innovation: A Systematic Literature Review and Development of a Research Agenda", in Proceedings of the 27th European Conference on Information Systems (ECIS). 2019: Stockholm \& Uppsala, Sweden. 
[34] Lusch, R.F. and S. Nambisan, "Service Innovation: A Service-Dominant Logic Perspective", MIS Quarterly, 39(1), 2015, pp. 155-175.

[35] Dougherty, D., "Organizing Practices in Services: Capturing Practice-Based Knowledge for Innovation", Strategic Organization, 2(1), 2004, pp. 35-64.

[36] Reichwald, R., K.M. Möslein, M. Kölling, and A.-K. Neyer, "Service-Innovation", CLIC executive briefing(001), 2008.

[37] Bullinger, H.-J., K.-P. Fähnrich, and T. Meiren, "Service engineering-methodical development of new service products", International Journal of Production Economics, 85(3), 2003, pp. 275-287.

[38] Brown, T., "Design Thinking", Harvard Business Review, 86(6), 2008, pp. 84-92.

[39] Ostrom, A.L., M.J. Bitner, S.W. Brown, K.A. Burkhard, M. Goul, V. Smith-Daniels, H. Demirkan, and E. Rabinovich, "Moving Forward and Making a Difference: Research Priorities for the Science of Service", Journal of Service Research, 13(1), 2010, pp. 4-36.

[40] Patrício, L., A. Gustafsson, and R. Fisk, "Upframing Service Design and Innovation for Research Impact", Journal of Service Research, 21(1), 2018, pp. 3-16.

[41] Kim, K.-J. and T. Meiren, "New Service Development Process", in Introduction to service engineering, G. Salvendy and W. Karwowski, Editors. 2010. John Wiley \& Sons: Hoboken, N.J.

[42] Möller, F., T.M. Guggenberger, and B. Otto, "Towards a Method for Design Principle Development in Information Systems", in Proceedings of the 5th International Conference on Design Science Research in Information Systems and Technology (DESRIST 2020). 2020: Kristiansand, Norway.

[43] Kühne, B., A. Zolnowski, J. Bornholt, and T. Böhmann, "Making Data Tangible for Data-driven Innovations in a Business Model Context", in Proceedings of the 25th Americas Conference on Information Systems (AMCIS). 2019: Cancun, Mexico.

[44] Blaschke, M., U. Riss, K. Haki, and S. Aier, "Design principles for digital value co-creation networks: a servicedominant logic perspective", Electronic Markets, 29(3), 2019, pp. 443-472.

[45] Hevner, A.R., S.T. March, J. Park, and S. Ram, "Design Science in Information Systems Research", MIS Quarterly, 28(1), 2004, pp. 75-105.

[46] Kuechler, B., Vaishnavi, V., "On Theory Development in Design Science Research: Anatomy of a Research Project", Eur. J. Inf. Syst. 17, 2008, pp. 489-504.

[47] Schultze, U. and M. Avital, "Designing interviews to generate rich data for information systems research", Information and Organization, 21(1), 2011, pp. 1-16.
[48] Merton, R.K. and P.L. Kendall, "The Focused Interview", American Journal of Sociology, 51(6), 1946, pp. 541-557.

[49] Chandra, L., S. Seidel, and S. Gregor, "Prescriptive Knowledge in IS Research: Conceptualizing Design Principles in Terms of Materiality, Action, and Boundary Conditions", in Proceedings of the 48th Hawaii International Conference on System Sciences (HICSS), HI, USA. 2015. IEEE.

[50] Bryman, A., Social research methods, Oxford University Press, Oxford, 2016.

[51] Aversa, P., S. Haefliger, A. Rossi, and C. Baden-Fuller, "From Business Model to Business Modelling: Modularity and Manipulation", in Business Models and Modelling, C. Baden-Fuller and V. Mangematin, Editors. 2015. Emerald Group Publishing Limited.

[52] Goldstein, S.M., R. Johnston, J. Duffy, and J. Rao, "The service concept: the missing link in service design research?", Journal of Operations Management, 20(2), 2002, pp. 121-134.

[53] Krippendorff, K., "Content Analysis: An Introduction to Its Methodology", 2013.

[54] Pratt, M.G., "Fitting Oval Pegs Into Round Holes", Organizational Research Methods, 11(3), 2008, pp. 481509 .

[55] Goldkuhl, G., "Design Theories in Information Systems - A Need for Multi-Grounding", Journal of Information Technology Theory and Application (JITTA), 6(2), 2004, pp. 59-72.

[56] Walls, J.G., G.R. Widmeyer, and O.A. El Sawy, "Building an Information System Design Theory for Vigilant EIS", Information Systems Research, 3(1), 1992, pp. 36-59.

[57] Gregor, S., "The nature of theory in Information Systems", MIS Quarterly, 30(3), 2006, pp. 611-642.

[58] Otto, B., "Quality and Value of the Data Resource in Large Enterprises", Information Systems Management, 32(3), 2015, pp. 234-251.

[59] Storey, C., P. Cankurtaran, P. Papastathopoulou, and E.J. Hultink, "Success Factors for Service Innovation: A Meta-Analysis", Journal of Product Innovation Management, 33(5), 2016, pp. 527-548.

[60] Gelhaar, J. and B. Otto, "Challenges in the Emergence of Data Ecosystems", in Proceedings of the 24th Pacific Asia Conference on Information Systems (PACIS). 2020.

[61] Lis, D. and B. Otto, "Data Governance in Data Ecosystems - Insights from Organizations", in Proceedings of the 26th Americas Conference on Information Systems (AMCIS). 2020: Salt Lake City, USA. 